\title{
Effect of choline chloride in allergen-induced mouse model of airway inflammation
}

\author{
A.K. Mehta*\#, S.N. Gaur", N. Arora* and B.P. Singh*
}

ABSTRACT: The incidence of asthma has increased the world over, and current therapies for the disease suffer from potential side-effects. This has created an opportunity to develop novel therapeutic approaches. Here, the anti-inflammatory activity of choline was investigated in a mouse model of allergic airway inflammation.

Choline $\left(1 \mathrm{mg} \cdot \mathrm{kg}^{-1}\right)$ was administered via oral gavage or intranasally before and after ovalbumin (OVA) challenge in sensitised mice. Airway hyperresponsiveness (AHR) to methacholine was measured in the mice by whole-body plethysmography. Type-2 T-helper cell cytokine and leukotriene levels were estimated in bronchoalveolar lavage fluid (BALF) and spleen culture supernatant by ELISA. Eosinophil peroxidase activity was also determined in the BALF supernatant.

Choline treatment in sensitised mice before OVA challenge via oral/intranasal routes significantly inhibited eosinophilic airway inflammation and eosinophil peroxidase activity. It also reduced immunoglobulin E and G1 production and inhibited the release of type-2 T-helper cell cytokines and leukotrienes. However, the development of AHR was prevented effectively by intranasal choline treatment. Most importantly, choline treatment after OVA challenge by both routes could reverse established asthmatic conditions in mice by inhibiting AHR, eosinophilic airway inflammation and other inflammatory parameters.

This study provides a new therapeutic approach for controlling as well as preventing asthma exacerbations.

KEYWORDS: Airway inflammation, animal model, asthma, choline, eosinophils

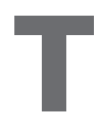
he incidence of asthma and allergic disorders has increased two-fold since the early 1980s [1]. Asthma is a chronic inflammatory disease characterised by eosinophilic infiltration into the bronchial mucosa, airway hyperresponsiveness (AHR) and intermittent pulmonary obstruction. It is partly mediated by CD4+ T-cells that activate numerous airway inflammatory cells, such as T-cells and eosinophils, leading to morphological changes in airway tissue and increased AHR [2]. Furthermore, cysteinyl (Cys) leukotrienes (LTs; $\mathrm{LTC}_{4}, \mathrm{LTD}_{4}$ and $\mathrm{LTE}_{4}$ ) induce AHR in asthmatics, followed by bronchoconstriction, mucus secretion and promotion of eosinophil chemotaxis [3, 4].

Several therapeutic interventions, such as glucocorticoids, have focused on the attenuation of airway inflammation. Such drugs relieve symptoms but do not reverse disease progression or cure the disease, and have potential side-effects that limit their usefulness [5]. LT modifiers, a new class of anti-asthma drug, have been associated with liver toxicity [6]. Therefore, new drugs are required to control immune inflammation with minimal or no side-effects.

Choline, a lipotropic factor, plays a role in the mobilisation of fats in liver, essential for acetylcholine (ACh) formation [7] and used for phosphatidyl choline (PC) synthesis by a de novo pathway [8]. It has shown anti-inflammatory activity in an arthritis animal model [9]. Choline magnesium trisalicylate improved symptoms in aspirin-induced asthma patients [10]. Furthermore, tricholine citrate reduced symptoms and drug requirement in asthma [11, 12]. These reports suggest a benefit of choline in asthma, but evidence is lacking concerning its action on the airways. The present study investigates the potential of choline in inhibiting pulmonary infiltration of inflammatory cells and AHR in an ovalbumin (OVA)-induced mouse model of allergic airway inflammation.

\section{AFFILIATIONS}

*Allergy and Immunology Section, Institute of Genomics and Integrative Biology, and

-Dept of Respiratory Medicine, Vallabhbhai Patel Chest Institute, University of Delhi, Delhi, and \#Dept of Biotechnology, University of Pune, Pune, India

\section{CORRESPONDENCE}

B.P. Singh

Allergy and Immunology Section Room No. 509

Institute of Genomics and Integrative Biology

Delhi University Campus

Mall Road

Delhi-110007

India

Fax: 911127667471

E-mail: singhbp1951@yahoo.com

Received:

February 162007

Accepted after revision:

June 202007

\section{SUPPORT STATEMENT}

This study was supported by the Asthma and Allergy Mitigation Task Force of the Council of Scientific and Industrial Research (New Delhi, India). A.K. Mehta is a Senior Research Fellow of the Indian Council of Medical Research (New Delhi, India).

STATEMENT OF INTEREST None declared. 


\section{METHODS}

\section{Sensitisation and treatment}

Female BALB/c mice aged 6-8 weeks $(n=100)$ were obtained from the National Institute of Virology (Pune, India). The animal ethics committee of the Institute of Genomics and Integrative Biology (Delhi, India) approved the study protocol. Choline chloride (Sigma, St Louis, MO, USA) was administered via oral gavage or intranasally (i.n.) before and after OVA challenge in sensitised mice undergoing two different protocols.

Under protocol A, the mice were randomly divided into five groups (10 mice in each). The control group was sensitised, challenged and treated with $100 \mu \mathrm{L} 0.9 \% \mathrm{NaCl}$. The experimental groups were sensitised intraperitoneally (i.p.) with $100 \mu \mathrm{g}$ OVA adsorbed on $2 \mathrm{mg} \mathrm{Al}(\mathrm{OH})_{3}$ in $100 \mu \mathrm{L}$ saline on days 0,7 and 14 . They were challenged with $2.5 \%$ aerosolised OVA in saline for $30 \mathrm{~min}$ in a Plexiglas chamber using a nebuliser (Omron, Tokyo, Japan) on days 25-27. OVAsensitised and -challenged mice were treated with: 1) $100 \mu \mathrm{L}$ saline; 2) $100 \mu \mathrm{L} 1 \mathrm{mg} \cdot \mathrm{kg}^{-1}$ choline in saline (orally) $1 \mathrm{~h}$ before each OVA challenge on days 25-27; 3) $50 \mu \mathrm{L} 1 \mathrm{mg} \cdot \mathrm{kg}^{-1}$ choline in saline (i.n.) $30 \mathrm{~min}$ before each OVA challenge; and 4) $100 \mu \mathrm{L} 1 \mathrm{mg} \cdot \mathrm{kg}^{-1}$ dexamethasone phosphate in saline (i.p.) 30 min before each OVA challenge. After the final treatment/ challenge, AHR was measured on day 28 and the mice sacrificed on day 29.

Under protocol B, the mice were randomly divided into five groups (10 mice in each) and sensitised as for protocol A. They were then challenged with $2.5 \%$ aerosolised OVA in saline for $30 \mathrm{~min}$ on days $25-30$. After the last challenge ( $24 \mathrm{~h}$ ), the mice

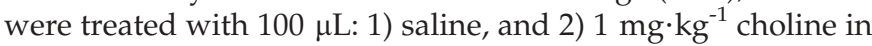
saline (orally) for 10 days (days 31-40). Similar doses of choline (i.n. in $50 \mu \mathrm{L}$ saline) and dexamethasone (i.p. in $100 \mu \mathrm{L}$ saline) were given on alternate days during days 31-40. Finally, a booster OVA challenge was performed on day 38. AHR was measured on day 41, after the challenge/treatment, and the mice sacrificed on day 42. The control group was sensitised, challenged and treated with $100 \mu \mathrm{L}$ saline. Mice receiving the dose i.n. were lightly anaesthetised (3\% isofluorane) before each dose. A dose of $1 \mathrm{mg} \cdot \mathrm{kg}^{-1}$ choline chloride was selected for all experiments on the basis of dose-response analysis (fig. 1).

\section{Determination of $\mathbf{A H R}$}

Airway reactivity in response to methacholine ( $\mathrm{MCh}$; Sigma) was measured in conscious unrestrained mice in a preconditioned whole-body plethysmograph (Buxco Electronics, Inc., Troy, NY, USA). Five mice from each group received nebulised PBS, followed by increasing concentrations of MCh (4$50 \mathrm{mg} \cdot \mathrm{mL}^{-1}$ ) to induce bronchoconstriction. Lung function was recorded and calculated as enhanced pause (Penh), which correlates with pulmonary resistance [13].

\section{Collection of bronchoalveolar lavage fluid and blood}

After the final airway challenge, mice were sacrificed using sodium pentobarbital $\left(100 \mathrm{mg} \cdot \mathrm{kg}\right.$ body weight ${ }^{-1}$, i.p.). Blood was collected after cardiac puncture for the total and differential cell counts. Sera were separated and used for analysis of serum immunoglobulin (Ig). The trachea was cannulated after collection of the blood. The lungs were lavaged three times with $0.5 \mathrm{~mL}$ chilled saline, and $\sim 1.5 \mathrm{~mL}$ was recovered from each mouse. Total cell counts in bronchoalvolar lavage fluid (BALF) were determined using a haemocytometer and light microscopy. Each BALF sample was centrifuged for $10 \mathrm{~min}$ at $400 \times g$ at $4^{\circ} \mathrm{C}$. The cell pellets were resuspended in $1 \mathrm{~mL}$ PBS and BALF cell smears were stained with Leishman's stain. BALF eosinophils were identified (percentage) by counting a minimum of 200 cells at high magnification $(\times 400)$. Absolute eosinophil numbers were calculated by multiplying total cell counts by the percentage of eosinophil in BALF cell pellets.

\section{Determination of eosinophil peroxidase activity}

Eosinophil peroxidase (EPO) levels in BALF supernatant were determined as described previously [14]. Briefly, $100 \mu \mathrm{L}$ substrate solution, containing $0.1 \mathrm{mM}$ o-phenylenediamine dihydrochloride (OPD; Sigma), 0.1\% Triton X-100 and $1 \mathrm{mM}$ hydrogen peroxide in $0.05 \mathrm{M}$ tris(hydroxymethyl)aminomethane (Tris)- $\mathrm{HCl}$ ( $\mathrm{pH} 8.0$ ), was added to $100 \mu \mathrm{L}$ BALF supernatant in microtitre plates and incubated for $30 \mathrm{~min}$ at $37^{\circ} \mathrm{C}$. The reaction was stopped by adding $50 \mu \mathrm{L} 4 \mathrm{M}$ sulphuric acid and the absorbance read at $492 \mathrm{~nm}$.

\section{Histopathology}

Lungs were inflated and fixed with $10 \%$ neutral buffered formalin. After fixation, lung sections of $4 \mu \mathrm{m}$ were cut and stained with haematoxylin-eosin (H\&E) or alcian blue/ periodic acid-Schiff (AB/PAS) for histological evaluation and monitoring of inflammatory cells and mucus production. Sections were scanned, using light microscopy, for antigeninduced peribronchial and perivascular inflammation. The eosinophil or lymphocyte infiltration around the airways and proliferation of goblet cells in the bronchial epithelium were quantified and graded as: 0: not present, 1: very slight, 2: slight, 3: moderate, 4: moderate to marked, and 5: marked. An inflammatory reaction affecting $<20 \%$ of the airways was defined as 1 (i.e. $<20 \%$ goblet cells stained with AB/PAS), 2 was defined as $20-40 \%$ of the airways affected, 3 defined as $40-$ $60 \%, 4$ was $60-80 \%$ and 5 was defined as $>80 \%$ of the airways affected [15].

\section{Splenocyte culture}

For in-vitro experiments, splenocytes $\left(5 \times 10^{6}\right.$ cells $\left.\cdot \mathrm{mL}^{-1}\right)$ were cultured in RPMI 1640 medium (supplemented with $10 \%$ heatinactivated foetal bovine serum, $10 \mathrm{mM}$ hydroxyethyl piperazine ethane sulphonic acid ( $\mathrm{pH} 7.9), 2 \mathrm{mM}$ L-glutamine, $100 \mathrm{U} \cdot \mathrm{mL}^{-1}$ penicillin and $100 \mu \mathrm{g} \cdot \mathrm{mL}^{-1}$ streptomycin (Sigma)) and stimulated with $100 \mu \mathrm{g} \cdot \mathrm{mL}^{-1} \mathrm{OVA}$. Cells were cultured for $72 \mathrm{~h}$ at $37^{\circ} \mathrm{C}$ in a carbon dioxide incubator. The culture supernatant was collected for measurement of cytokine and eicosanoid levels.

\section{Determination of specific antibody levels and cytokines by ELISA}

OVA-specific serum IgE, G1 and G2a titres were measured in duplicate by ELISA as previously described, with slight modification [16]. Briefly, microtitre plates (Nunc-Immuno ${ }^{\mathrm{TM}}$ Modules; Nunc, Roskilde, Denmark) were coated with $5 \mu \mathrm{g} \cdot \mathrm{mL}^{-1}$ OVA in $0.1 \mathrm{M}$ carbonate buffer ( $\mathrm{pH} 9.6$ ) and incubated overnight at $4{ }^{\circ} \mathrm{C}$. The plates were washed with PBS and blocked with $3 \%$ defatted milk for $3 \mathrm{~h}$ at $37^{\circ} \mathrm{C}$. The plates were incubated overnight at $4^{\circ} \mathrm{C}$ with mouse sera for 

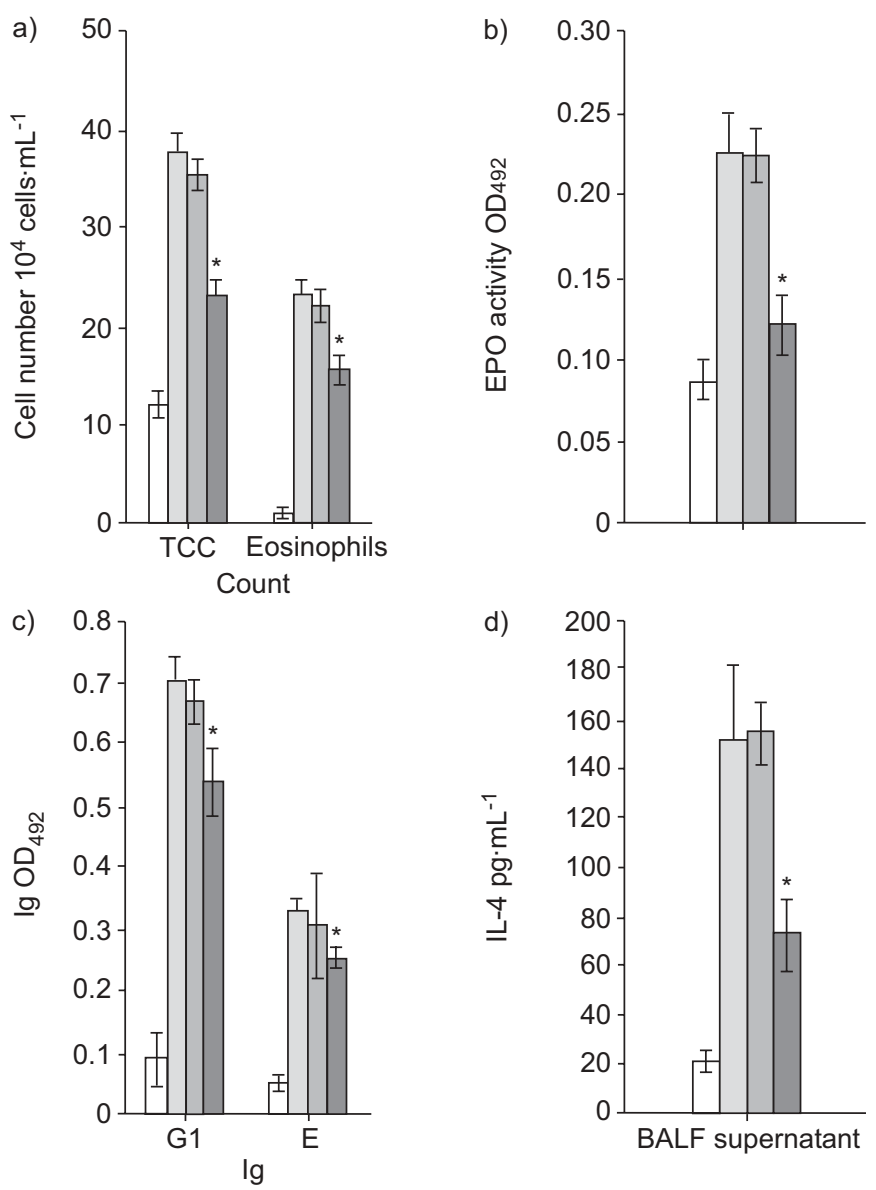

FIGURE 1. Dose-response analysis using a lower and higher dose of choline chloride: a) total cell count (TCC) and eosinophil number in bronchoalveolar lavage fluid (BALF); b) eosinophil peroxidase (EPO) activity in BALF supernatant; c) serum ovalbumin (OVA)-specific immunoglobulin (Ig) G1 and E levels; and d) interleukin (IL)4 level in BALF supernatant. $\square$ : normal control; 1 : OVA; $\mathbb{1}: 0.01 \mathrm{mg} \cdot \mathrm{kg}^{-1}$ choline chloride; : $1 \mathrm{mg} \cdot \mathrm{kg}^{-1}$ choline chloride. $\mathrm{OD}_{492}$ : optical density at $492 \mathrm{~nm}$. Data are presented as mean $\pm S D . n=5$ mice per group. *: $p<0.05$ versus OVA mice.

individual $\operatorname{IgE}$ (1:10), G1 (1:50) and G2a (1:50) estimation. After washing with $0.05 \%$ Tween 20 in PBS and PBS, the plates were incubated for $3 \mathrm{~h}$ at $37^{\circ} \mathrm{C}$ with IgG1-peroxidase and IgG2aperoxidase (1:1000 PBS; BD Pharmingen, San Diego, CA, USA).

For $\operatorname{IgE}$, biotinylated antimouse $\operatorname{IgE}$ (BD Pharmingen; $2 \mu \mathrm{g} \cdot \mathrm{mL}^{-1}$ ) was added and the plates incubated for $90 \mathrm{~min}$ at room temperature. Following washing, incubation with streptavidin-peroxidase (BD Pharmingen; 1:1,000) was performed for $30 \mathrm{~min}$. The plates were washed and developed using OPD and the absorbance read at $492 \mathrm{~nm}$.

Interleukin (IL)-4 and -5 and interferon (IFN)- $\gamma$ levels were determined in undiluted BALF and culture supernatants in duplicate by ELISA, using paired antibodies according to the manufacturer's instructions (BD Pharmingen). The detection limits for IL-4, IL-5 and IFN- $\gamma$ were $7.8,15.6$ and $31.3 \mathrm{pg} \cdot \mathrm{mL}^{-1}$, respectively.

\section{Eicosanoid assays}

Undiluted BALF and culture supernatants were assayed in duplicate for $\mathrm{LTB}_{4}$ and Cys-LT using enzyme immunoassay kits (Cayman Chemical Co., Ann Arbor, MI, USA) according to the manufacturer's instructions. The detection limit for $\mathrm{LTB}_{4}$ and Cys-LT was $13 \mathrm{pg} \cdot \mathrm{mL}^{-1}$.

\section{Statistical analysis}

Groups were analysed using one-way ANOVA followed by Dunnett's multiple comparison test to examine differences between OVA-challenged saline-treated and choline-treated groups. Differences were considered significant at $\mathrm{p}<0.05$. Data are presented as mean \pm SD for each group.

\section{RESULTS}

\section{Effect of choline on allergen-induced eosinophilic airway inflammation}

Two different schedules of choline administration, before (preventive) and after (therapeutic) OVA challenge, were used to demonstrate the changes occurring after treatment in an allergen-induced inflammatory model of airway disease. A significant reduction in BALF cell count and eosinophil number were observed following choline treatment orally $(p<0.05)$ or i.n. $(\mathrm{p}<0.05)$, as compared to OVA-challenged saline-treated mice in both study protocols (figs $2 \mathrm{a}$ and $3 \mathrm{a}$ ). Similar results were obtained for peripheral blood count and eosinophil number (data not shown). Treatment with dexamethasone also led to significant reduction in eosinophil numbers $(\mathrm{p}<0.05)$.

The recruitment of inflammatory cells into the airways was monitored in the choline-treated groups compared with the OVA-challenged saline-treated group using H\&E staining (figs 4 and 5). In the OVA-challenged saline-treated group, numerous eosinophils were observed in the lung interstitium around airways and blood vessels, along with narrowing of the airway lumen (figs $4 \mathrm{~b}$ and $5 \mathrm{~b}$ ). Choline treatment, given orally or i.n., significantly reduced the inflammatory infiltrates in both protocols (figs $4 c, 4 d, 5 c$ and $5 d$ ). Mice treated with dexamethasone showed reduced inflammation and eosinophil infiltration into lungs (figs $4 \mathrm{e}$ and 5e). These results were confirmed by a reduction in total inflammation score in choline-treated groups compared to saline-treated groups $(\mathrm{p}<0.05$; figs $4 \mathrm{f}$ and $5 \mathrm{f})$.

In control groups, either no or very few $\mathrm{AB} / \mathrm{PAS}$-positive epithelial cells were observed (figs $6 a$ and 7a). Conversely, many epithelial cells were enlarged in OVA-challenged mice, occurring along with airway narrowing and mucus plugging with increased goblet cell hyperplasia visualised using AB/ PAS staining (figs $6 \mathrm{~b}$ and $7 \mathrm{~b}$ ). Choline treatment before challenge by either route (oral/i.n.) inhibited mucus production and goblet cell hyperplasia (fig $6 \mathrm{c}$ and d). Choline treatment downregulated the accumulation of mucus in the airways and prevented airway obstruction after antigen challenge (figs $7 \mathrm{a}$ and $\mathrm{b}$ ). There was a substantial reduction in total inflammation score in choline-treated mice compared to saline-treated mice $(p<0.05$; figs $6 f$ and $7 f)$.

\section{Effect of choline on MCh-induced AHR}

MCh-induced airway resistance was measured on days 28 and 41 in both protocols. OVA-challenged saline-treated mice developed AHR, as demonstrated by a dose-dependent elevation of Penh in response to Mch (figs $2 b$ and $3 b$ ). Treatment with oral choline before challenge resulted in a modest, although not significant, decrease in AHR. However, 

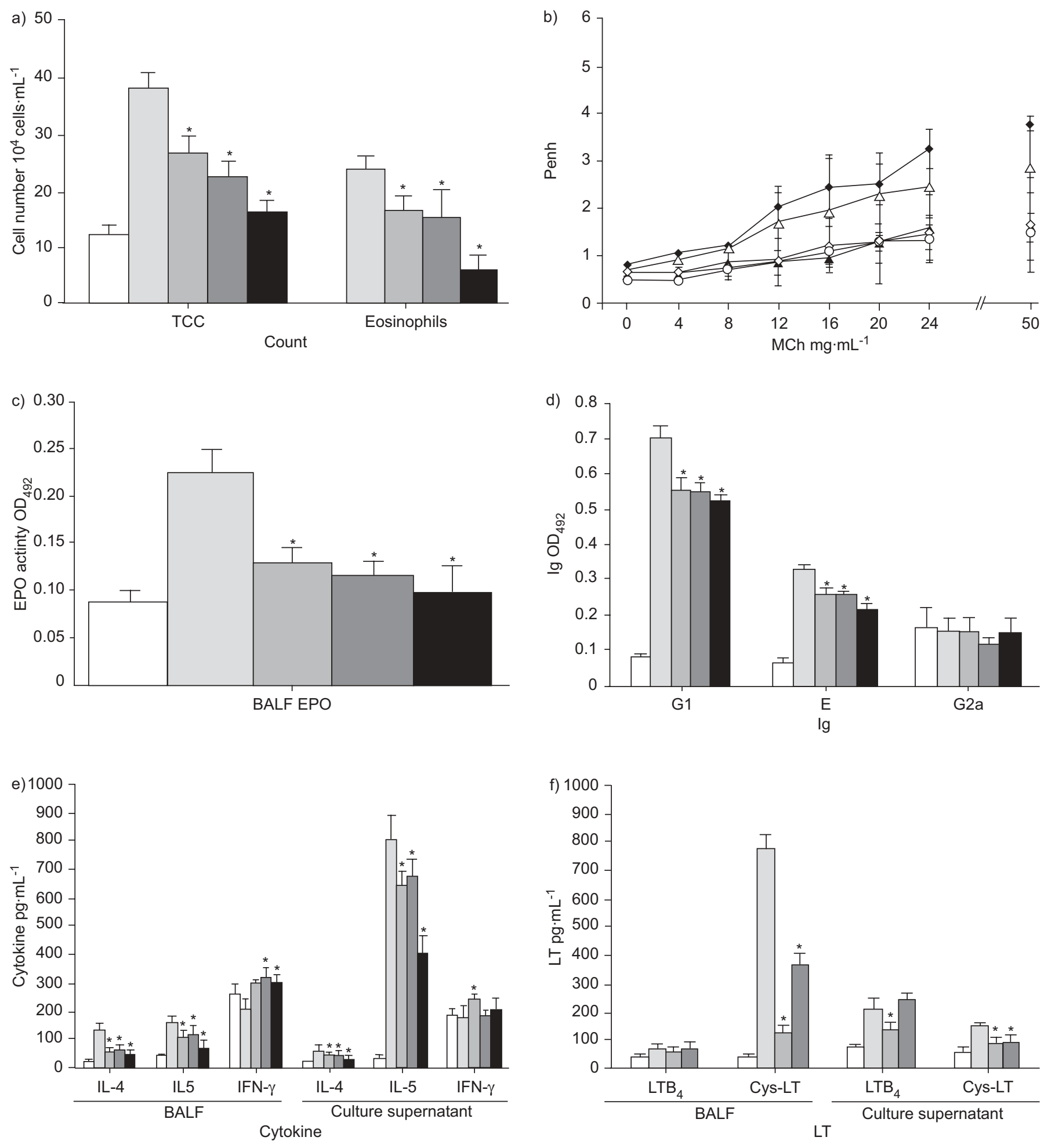

FIGURE 2. Effect of choline administration before ovalbumin (OVA) challenge in OVA-sensitised BALB/c mice. a) Total cell count (TCC) and eosinophil number in bronchoalveolar lavage fluid (BALF). b) Airway hyperresponsiveness (AHR) induced by increasing doses of methacholine (MCh) in choline- and saline-treated OVAchallenged mice. c) Eosinophil peroxidase (EPO) activity in BALF supernatant. d) Serum OVA-specific immunoglobulin (Ig) G1, E and G2a levels. e) Cytokine levels in BALF and spleen culture supernatant. Interferon (IFN)- $\gamma$ release $(p<0.05)$ in choline treated in BALF and culture supernatant as compared to normal control mice. $f$ ) Leukotriene $(\mathrm{LT}) \mathrm{B}_{4}$ and cysteinyl LT (Cys-LT) level in BALF and spleen culture supernatant by enzyme immunoassay. $\square$ and $\mathrm{O}$ : normal control; $\square$ and $\bullet$ : OVA; $\square$ and $\triangle:$ oral choline; $\mathbf{n}$ and $\mathbf{\Lambda}$ : intranasal choline; $\boldsymbol{\square}$ and $\diamond$ : dexamethasone. Choline given before challenge prevented AHR and eosinophilic airway inflammation. Penh: enhanced pause; $\mathrm{OD}_{492}$ : optical density at $492 \mathrm{~nm}$; IL; interleukin. Data are presented as mean $\pm \mathrm{SD}$. $\mathrm{n}=5$ mice per group. ${ }^{*}$ : $\mathrm{p}<0.05$ versus OVA mice (versus normal control for IFN- $\gamma$ release in choline-treated mice). 

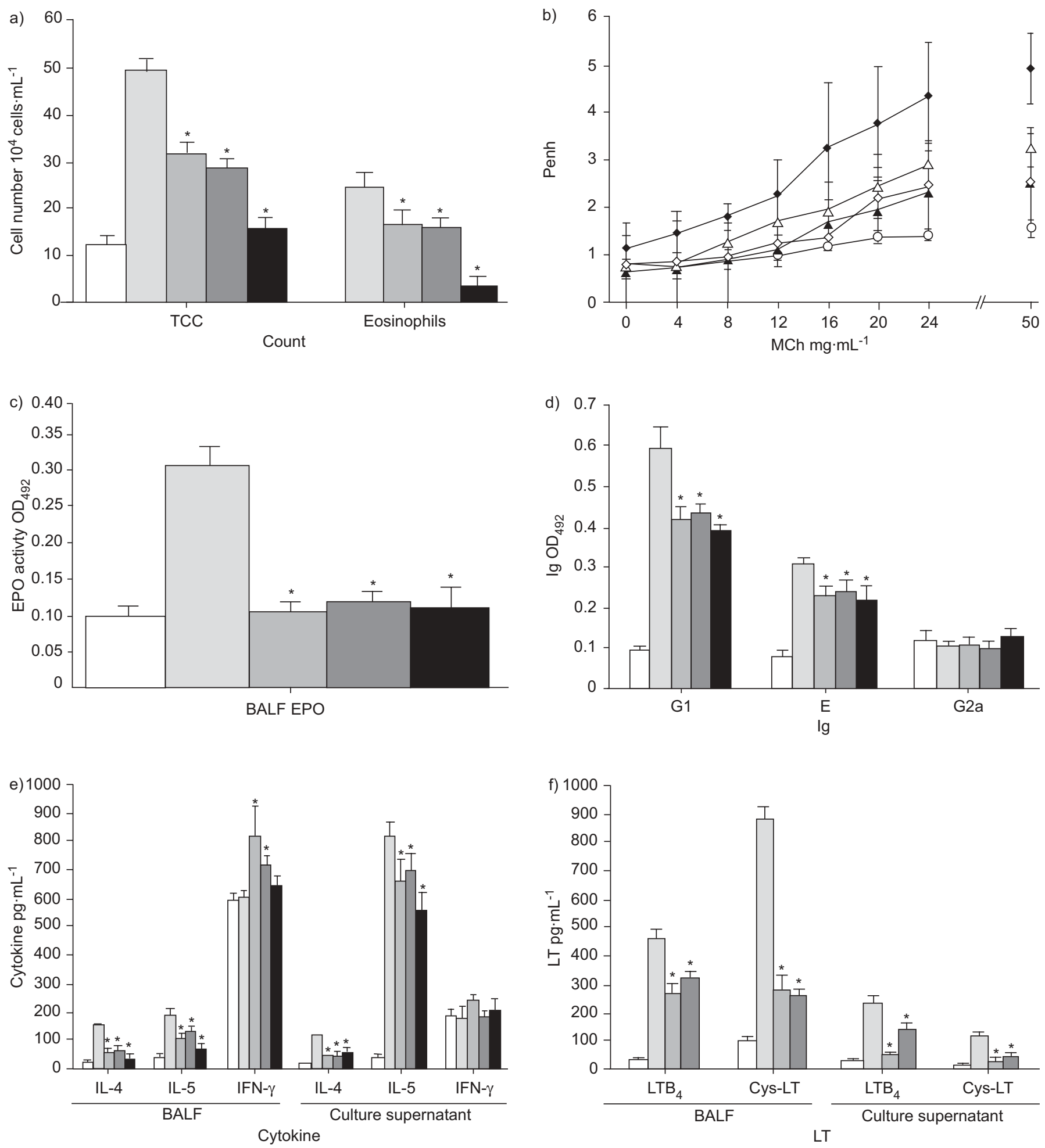

FIGURE 3. Effect of choline administration after ovalbumin (OVA) challenge in a mouse model of allergic inflammation. a) Total cell count (TCC) and eosinophil number in bronchoalveolar lavage fluid (BALF). b) Airway hyperresponsiveness (AHR) induced by increasing doses of methacholine (MCh) in choline- and saline-treated OVAchallenged mice. c) Eosinophil peroxidase (EPO) activity in BALF supernatant. d) Serum OVA-specific immunoglobulin (Ig) G1, E and G2a levels. e) Cytokine levels in BALF and spleen culture supernatant. Choline (oral and intranasal (i.n.)) induces significant interferon (IFN)- $\gamma$ release $(p<0.05)$ in BALF compared to normal control mice. f) Leukotriene (LT)B 4 and cysteinyl LT (Cys-LT) level in BALF and spleen culture supernatant. $\square$ and $O$ : normal control; $\square$ and $\bullet$ : OVA; $\square$ and $\triangle$ : oral choline; $\square$ and $\mathbf{\Delta}$ : i.n. choline; and $\diamond$ : dexamethasone. Penh: enhanced pause; $\mathrm{OD}_{492}$ : optical density at $492 \mathrm{~nm}$; IL; interleukin. Data are presented as mean $\pm \mathrm{SD}$. $\mathrm{n}=5 \mathrm{mice}$ per group. *: $p<0.05$ versus OVA mice (versus normal control for IFN- $\gamma$ release in choline-treated mice). 

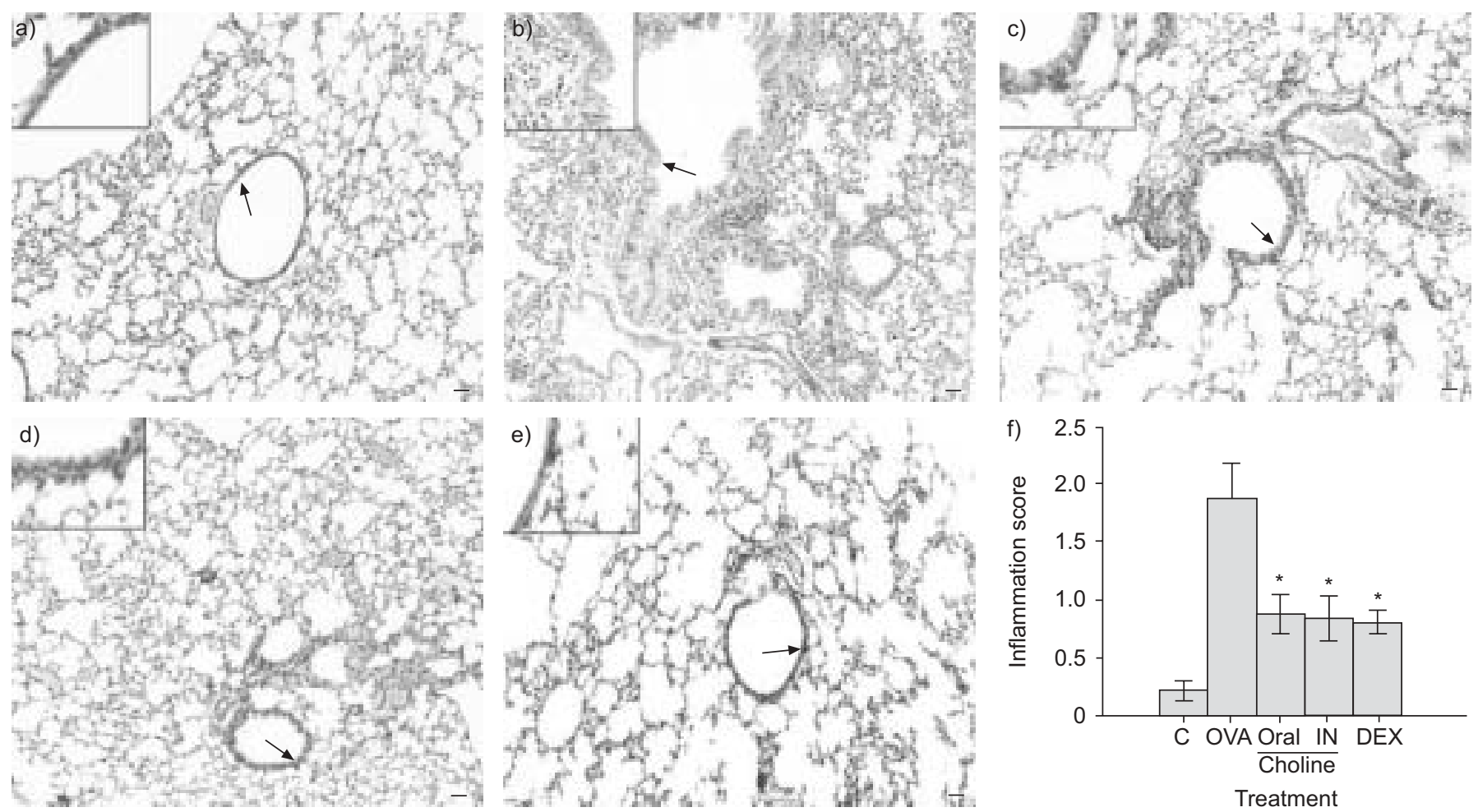

FIGURE 4. Effect of choline given before challenge on airway inflammation. Representative haematoxylin-eosin stained sections of lungs from: a) normal mice, salinesensitised and challenged (C); b) ovalbumin (OVA)-challenged saline-treated mice; c) OVA-challenged mice treated with oral choline; d) OVA-challenged mice treated with intranasal (IN) choline; and e) OVA-challenged mice treated with dexamethasone (DEX). f) Total inflammation score on a scale of 0-4. Insets show higher magnifications of areas indicated by arrows. Data are presented as mean $\pm S D . n=5$ mice per group. Choline administration before challenge had a preventive effect on airway inflammation, with the total inflammation score being significantly reduced in the choline-treated groups. Scale bars $=100 \mu \mathrm{m} .{ }^{*}: \mathrm{p}<0.05$ versus OVA mice.

i.n. treatment resulted in a significant reduction in Penh $(\mathrm{p}<0.05)$ at Mch concentrations of $12-50 \mathrm{mg} \cdot \mathrm{mL}^{-1}$ (fig. $2 \mathrm{~b}$ ).

In protocol B, Penh significantly decreased with oral choline treatment $\left(20-50 \mathrm{mg} \cdot \mathrm{mL}^{-1}\right)$. However, i.n. treatment was more effective and showed a significant reduction in Penh $(p<0.05)$ at Mch concentrations of $4-50 \mathrm{mg} \cdot \mathrm{mL}^{-1} \quad$ (fig. $3 \mathrm{~b}$ ). Dexamethasone treatment inhibited the development of AHR in both study protocols $(\mathrm{p}<0.05)$.

\section{EPO activity in choline-treated mice}

Significantly, high levels of EPO, with increased numbers of eosinophils in BALF, were observed in saline-treated mice. However, choline treatment via both routes (figs $2 \mathrm{c}$ and $3 \mathrm{c}$ ) reduced EPO activity $(p<0.05)$ and thus reduced inflammation in the airways. Treatment with dexamethasone significantly reduced EPO activity in both protocols $(\mathrm{p}<0.05)$.

\section{Effect of choline on serum OVA-specific IgG1, E and G2a}

Oral and i.n. choline treatment resulted in a significant decrease in IgG1 and $\mathrm{E}(\mathrm{p}<0.05)$ levels in both study protocols (figs $2 \mathrm{~d}$ and $3 \mathrm{~d}$ ). Dexamethasone treatment also reduced IgG1 and $\mathrm{E}$ levels in mice. However, no significant difference was observed in IgG2a levels following choline treatment.

\section{Effect of choline on type-2 T-helper cell cytokine levels in $B A L F$ and culture supernatant}

IL-4 and -5 levels were remarkably reduced with choline treatment via the oral or i.n. route in BALF and in culture supernatants $(\mathrm{p}<0.05)$ (figs $2 \mathrm{e}$ and $3 \mathrm{e})$. Under protocol $\mathrm{A}$, i.n. choline treatment showed increased IFN- $\gamma$ levels in BALF $(p=0.035)$, but this was not the case in the oral treatment group $(p=0.149)$. Oral choline treatment induced IFN- $\gamma$ levels in spleen culture supernatant significantly $(\mathrm{p}<0.05)$ compared to i.n. treatment $(p=0.76)$. Under protocol $B$, both routes showed an increase in IFN- $\gamma$ levels in BALF compared to normal mice, but this was not observed for culture supernatant.

\section{Effect of choline on eicosanoid levels in bronchoalveolar lavage fluid and culture supernatant}

The $\mathrm{LTB}_{4}$ level was reduced in culture supernatant but not in BALF following oral choline treatment under protocol A (fig. 2f). However, $\mathrm{LTB}_{4}$ level showed a significant decrease in BALF as well as in culture supernatant $(p<0.05)$ with choline treatment by either route after challenge (fig. 3f).

Apart from $\mathrm{LTB}_{4}$, choline treatment strongly inhibited the release of Cys-LTs, not only in BALF but also in culture supernatant (figs. $2 \mathrm{f}$ and $3 \mathrm{f}$ ). This inhibition of Cys-LTs was observed in both protocols $(\mathrm{p}<0.05)$.

\section{DISCUSSION}

The identification of effective drugs for asthmatics has been relegated in recent years, especially for those who respond poorly to conventional therapy. Glucocorticosteroids, used for asthma treatment, are associated with systemic side-effects [17]. Consequently, there is need for the development of new agents for the treatment of airway diseases. 

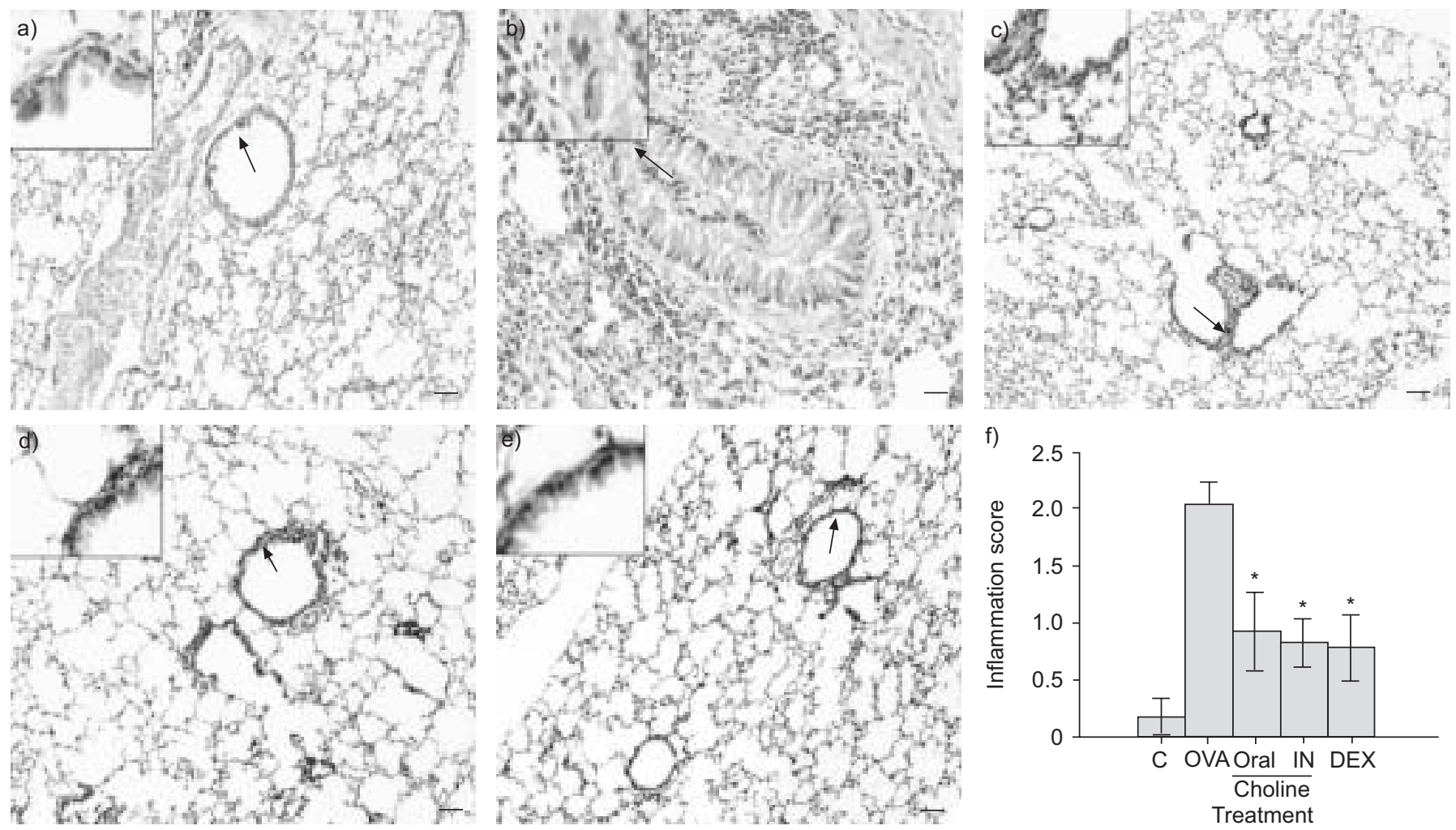

FIGURE 5. Effect of choline given after challenge on airway inflammation. Representative haematoxylin-eosin stained sections of lungs from: a) normal mice, salinesensitised and challenged (C); b) ovalbumin (OVA)-challenged saline-treated mice; c) OVA-challenged mice treated with oral choline; d) OVA-challenged mice treated with intranasal (IN) choline; and e) OVA-challenged mice treated with dexamethasone (DEX). f) Total inflammation score on a scale of 0-4. Insets show higher magnifications of areas indicated by arrows. Data are presented as mean $\pm \mathrm{SD}$. $\mathrm{n}=5$ mice per group. The total inflammation score was significantly reduced in the choline-treated groups. Scale bars $=100 \mu \mathrm{m} .{ }^{*}: \mathrm{p}<0.05$ versus OVA mice.

Nicotinic ACh receptor (nAChR) agonists are known for protective effects on the development of airway inflammation through the cholinergic anti-inflammatory pathway [18, 19]. Various inflammatory cells, such as eosinophils, lymphocytes, alveolar macrophages and airway smooth muscle cells express nAChRs. Agonists of nAChRs such as 1,1-dimethyl-4-phenylpiperazinium (DMPP) have been shown to have a potential downregulatory effect on eosinophil function, by inhibiting LTC $_{4}$ and eosinophil migration [20]. Choline, a selective agonist of $\alpha 7 \mathrm{nAChRs}$, suppressed passive joint anaphylaxis and showed anti-inflammatory activity in guinea pigs $[9,21$, 22]; however, its role in inhibiting eosinophilic inflammation is not known. In the present study, choline was demonstrated to be a potent inhibitor of airway inflammation, suppressing the accumulation of eosinophils and release of EPO into BALF, which may be mediated through activation of the $\alpha 7 \mathrm{nAChR}$ via the cholinergic anti-inflammatory pathway.

Eosinophils, on activation, release eosinophil cationic protein, major basic protein and $\mathrm{EPO}$, levels of which correlate with disease severity or AHR [23, 24]. In the present study, choline administration was effective in inhibiting AHR both before and after OVA challenge. The data from choline treatment is encouraging as the resolution of AHR may be associated with loss of eosinophil activation. Choline administered via the i.n. route gives a localised effect, whereas the oral route gives a systemic effect, reducing AHR. Aerosol therapy via the i.n. route is the preferred asthma therapy for adults and children, since it offers rapid onset of drug action directly into the target organs, requires smaller doses and reduces systemic effects.

Clinical and experimental evidence implicate type-2 T-helper cell cytokines in orchestration of the inflammatory response and AHR in asthma [2]. In the present study, the antiinflammatory effects of choline were at least partly mediated by suppression of type-2 T-helper cell cytokine levels in BALF and culture supernatant, with significant decreases in $\operatorname{IgE}$ and G1. The IL-4/IFN- $\gamma$ ratio in BALF also decreased in cholinetreated mice (data not shown). The reduction in the level of IL-5, a potential activation and survival factor for eosinophils, occurred concomitantly with the loss of EPO activity in BALF supernatant.

LTs are the key mediators of allergen-induced airway eosinophil infiltration and mucus release [3]. High levels of $\mathrm{LTB}_{4}$ and Cys-LTs were demonstrated in the BALF of asthmatics $[25,26]$. Cys- $\mathrm{LT}_{1}$ receptors are expressed on eosinophils, and their activation by Cys-LTs induces eosinophil infiltration into airways; they are thus considered a potent eosinophil chemoattractant [27]. Similarly, choline (nAChR agonist) treatment also inhibited the release of Cys-LTs and eosinophilic inflammation; in the allergen-induced airway, eosinophil infiltration may be mediated through the activation of the $\alpha 7 \mathrm{nAChR}$, as evidenced by nAChR agonist DMPP [20], and, interestingly, suppressed mucus hyperproduction. 

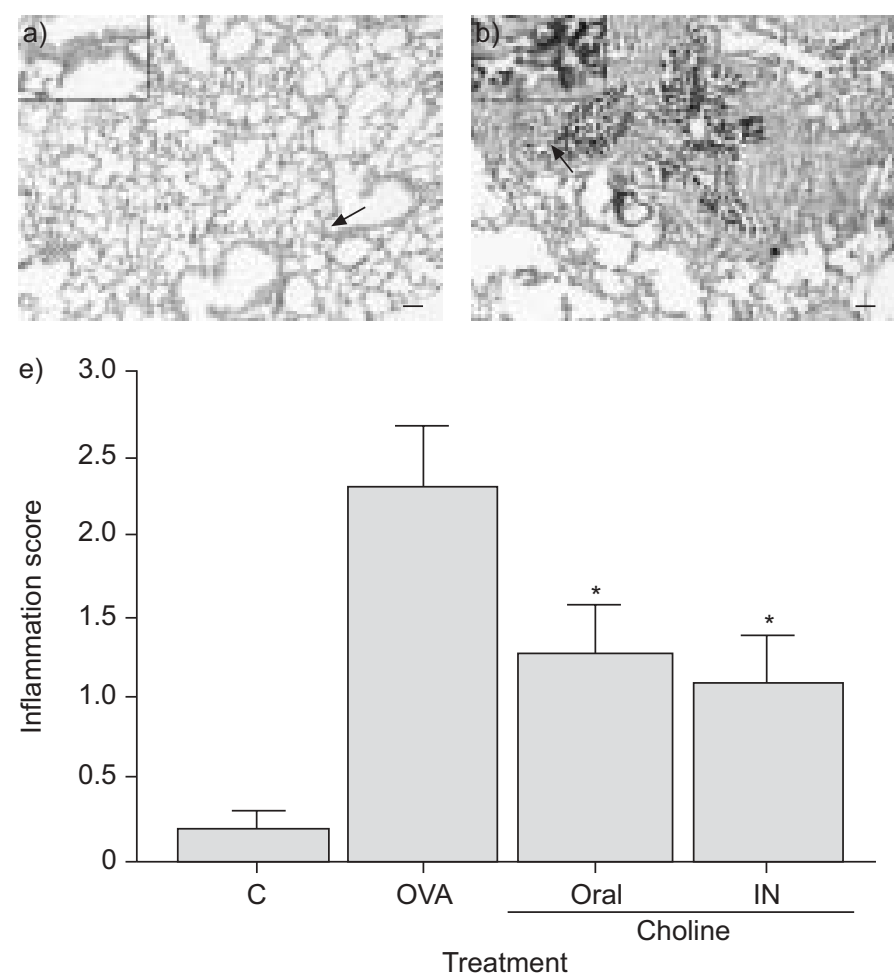

Choline, a dietary component, is important for the structural integrity of cell membranes, methyl metabolism, cholinergic neurotransmission, transmembrane signalling, lipid and cholesterol transport, and metabolism. Its deficiency results in loss of membrane PC and induction of apoptosis in PC12 cells in vitro [28]. It is involved in eliciting a variety of pharmacological effects in many diseases, including stroke, dementia, Alzheimer's disease, Parkinson's disease, etc. [29-32].
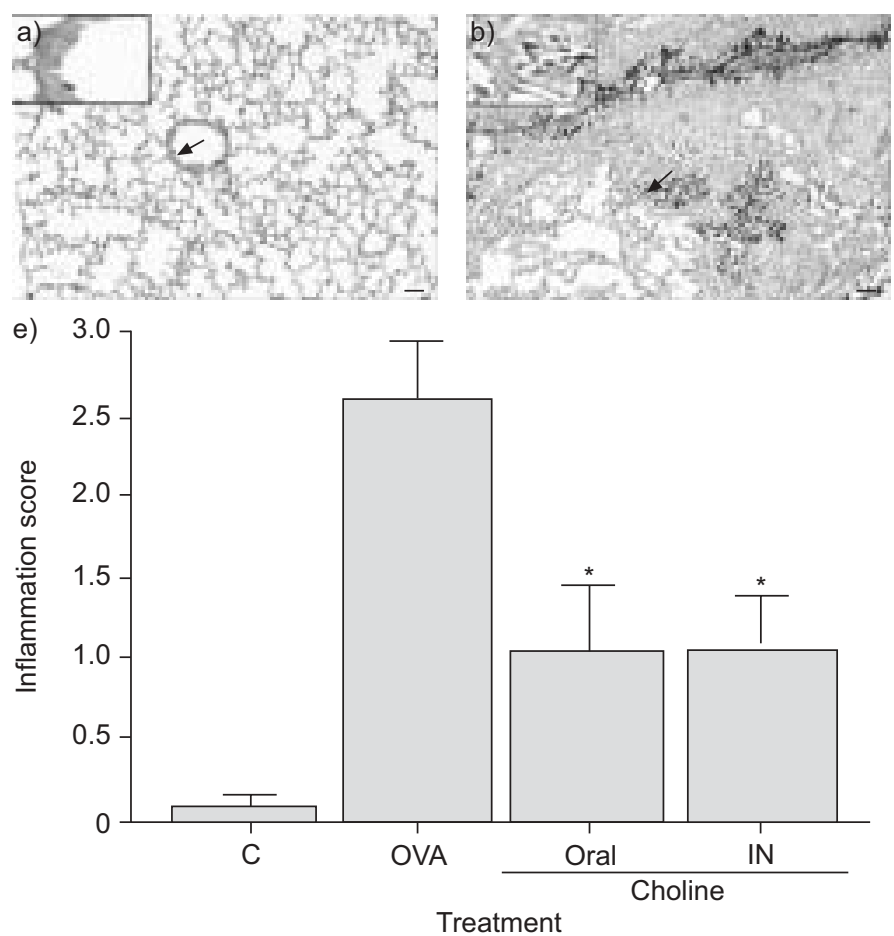
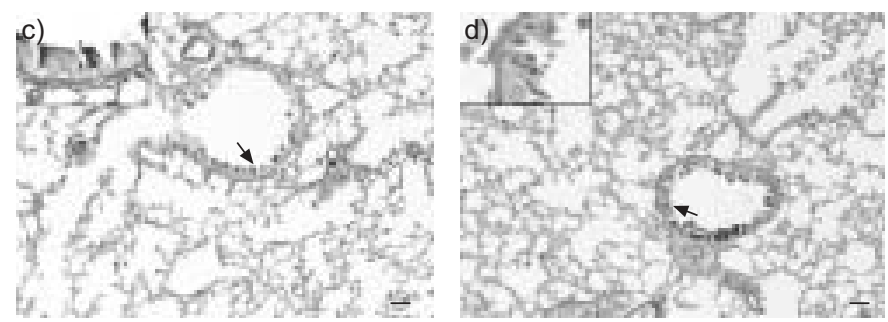

FIGURE 6. Alcian blue/periodic acid-Schiff staining of lung sections from mice in the first protocol. Lung histology of: a) normal mice, saline sensitised and challenged (C); b) ovalbumin (OVA)-challenged saline-treated mice; c) OVAchallenged mice treated with oral choline; and d) OVA-challenged mice treated with intranasal (IN) choline. e) The degree of infiltration of goblet cells was estimated on a scale of $0-4$. Insets show higher magnifications of areas indicated by arrows. Data are presented as mean \pm SD. $n=5$ mice per group. The total inflammation score was significantly reduced in the choline-treated groups. Scale bars $=100 \mu \mathrm{m}$. *: $p<0.05$ versus OVA mice.

Previously, asthma patients have shown improvement in symptom score on oral choline administration [11, 12], but this lacks experimental verification. Recently, choline has been shown to produce antinociceptive effects against inflammatory pain that are blocked by the $\alpha 7 \mathrm{nAChR}$ antagonist methyllycaconitine citrate, which strongly supports the involvement of $\alpha 7 \mathrm{nAChRs}$ in the antinociception of choline [22]. Adverse effects with high intake of choline $\left(>10 \mathrm{~g} \cdot \mathrm{day}^{-1}\right)$ are fishy body
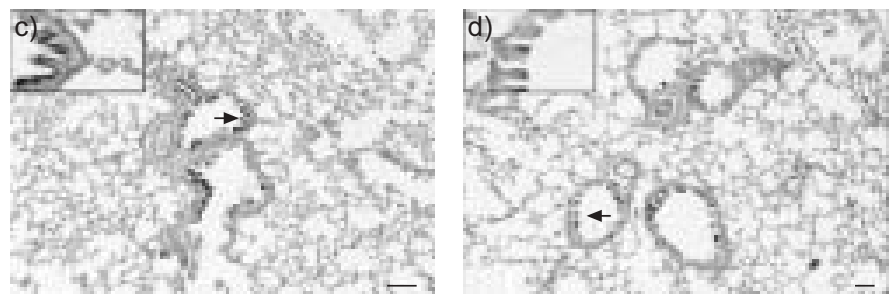

FIGURE 7. Alcian blue/periodic acid-Schiff staining of lung sections from mice in the second protocol. Lung histology of: a) normal mice, saline sensitised and challenged (C); b) ovalbumin (OVA)-challenged saline-treated mice; c) OVAchallenged mice treated with oral choline; and d) OVA-challenged mice treated with intranasal (IN) choline. e) The degree of infiltration of goblet cells was estimated on a scale of 0-4. Insets show higher magnifications of areas indicated by arrows. Data are presented as mean $\pm S D$ ( $n=5$ mice per group). The total inflammation score was significantly reduced in the choline-treated groups. Scale bars $=100 \mu \mathrm{m}$. *: $p<0.05$ versus OVA mice. 
odour, hypotension, nausea, sweating and diarrhoea, as reported earlier [31, 33].

PC is synthesised by de novo and transmethylation pathways, the two being reciprocally compensatory [8]. The activity of the transmethylation pathway is coupled to phospholipase $A_{2}$ activation, calcium influx and arachidonic acid formation, with release of LTs, prostaglandins and lyso-PC [34]. Choline supplementation increases membrane PC via the de novo pathway and inhibits the transmethylation pathway, thereby decreasing mediator release from human basophils [35].

Several of the functions that are governed by ACh are disturbed in allergic airway disease, and there is evidence that dysfunction of the cholinergic system is involved in the pathogenesis of asthma [36]. ACh synthesis requires uptake of choline, mediated by high-affinity choline transporter 1 , which is present in airway epithelial cells. Choline supplementation might restore this damage, since choline uptake via choline transporter 1 is the rate-limiting step in ACh synthesis by choline acetyltransferase [37]. However, it is difficult to explain this discrepancy based on the existing data.

The mechanism underlying the modulatory effect of choline is still not clear. Various inflammatory cells, such as lymphocytes, express most components of the cholinergic system, including $\mathrm{ACh}$, and the muscarinic $\mathrm{ACh}$ receptors and nAChRs, etc., which help in eliciting the intracellular $\mathrm{Ca}^{2+}$ response. Since the smooth muscle contraction induced by $\mathrm{MCh}$ is reduced by choline treatment, one of the major steps in smooth muscle contraction is intracellular calcium mobilisation [38]. In the present study $\mathrm{Ca}^{2+}$ level was not checked, but it has been demonstrated that nicotinic agonist can deplete the $\mathrm{Ca}^{2+}$ level in lymphocytes [39]. Similarly, in a rat model of endotoxic shock, choline restrained the increase in calcium influx and release of tumour necrosis factor- $\alpha$ by activated macrophages, possibly by increasing membrane PC, thereby preventing lung injury and improving survival [40]. This downregulatory effect of nicotinic agonist on $\mathrm{Ca}^{2+}$ mobilisation could be responsible for both the anti-inflammatory and bronchoprotective effects of choline.

In conclusion, choline was effective in inhibiting airway inflammation in a mouse model of airway hyperresponsiveness. However, further studies are required in order to elucidate its mechanism within this pre-clinical model, with possible subsequent investigations in asthma patients.

\section{ACKNOWLEDGEMENTS}

The authors would like to thank U. Mabalirajan (Institute of Genomics and Integrative Biology, Delhi, India) for help in recording airway hyperresponsiveness.

\section{REFERENCES}

1 Umetsu DT, McIntire JJ, Akbari O, Macaubas C, DeKruyff RH. Asthma: an epidemic of dysregulated immunity. Nat Immunol 2002; 3: 715-720.

2 Elias JA, Lee CG, Zheng T, Ma B, Homer RJ, Zhu Z. New insights into the pathogenesis of asthma. J Clin Invest 2003; 111: 291-297.

3 Henderson WR. The role of leukotrienes in inflammation. Ann Intern Med 1994; 121: 684-697.
4 Smith CM, Christie PE, Hawksworth RJ, Thien F, Lee TH. Urinary leukotriene $\mathrm{E}_{4}$ levels after allergen and exercise challenge in bronchial asthma. Am Rev Respir Dis 1991; 144: 1411-1413.

5 Barnes PJ, Pederson S. Efficacy and safety of inhaled corticosteroids in asthma. Am Rev Respir Dis 1993; 148: 1-26.

6 Horwitz RJ, McGill KA, Busse WW. The role of leukotriene modifiers in treatment of asthma. Am J Respir Crit Care Med 1998; 157: 1363-1371.

7 Blusztajn JK. Choline, a vital amine. Science 1998; 281: 794-795.

8 Pelech SL, Vance DE. Regulation of phosphatidyl choline synthesis. Biochim Biophys Acta 1984; 779: 217-251.

9 Ganley OH, Graessle OE, Robinson HJ. Anti-inflammatory activity of components obtained from egg-yolk, peanut oil and soya-bean lecithin. J Lab Clin Med 1958; 51: 709-714.

10 Szczeklik A, Nizankowska E, Dworski R. Choline magnesium trisalicylate in patients with aspirin-induced asthma. Eur Respir J 1990; 3: 535-539.

11 Gupta SK, Gaur SN. A placebo controlled trial of two dosages of LPC antagonist-choline in the management of bronchial asthma. Indian J Chest Dis Allied Sci 1997; 39: 149-156.

12 Gaur SN, Agarwal G, Gupta SK. Use of LPC antagonist, choline, in the management of bronchial asthma. Indian J Chest Dis Allied Sci 1997; 39: 107-113.

13 Lundblad LKA, Irvin CG, Adler A, Bates JH. A reevaluation of the validity of unrestrained plethysmography in mice. J Appl Physiol 2002; 93: 1198-1207.

14 Tomkinson A, Cielsewicz G, Duez C, Larson KA, Lee JJ, Gelfand EW. Temporal association between airway hyperresponsiveness and airway eosinophilia in ovalbuminsensitized mice. Am J Respir Crit Care Med 2001; 163: 721-730.

15 Inoue $\mathrm{K}$, Takano $\mathrm{H}$, Hiyoshi $\mathrm{K}$, et al. Naphthoquinone enhances antigen-related airway inflammation in mice. Eur Respir J 2007; 29: 259-267.

16 Singh AK, Mehta AK, Sridhara S, et al. Allergenicity assessment of transgenic mustard (Brassica juncea) expressing bacterial codA gene. Allergy 2006; 61: 491-497.

17 Lipworth BJ. Systemic adverse effects of inhaled corticosteroid therapy: a systematic review and meta-analysis. Arch Intern Med 1999; 159: 941-955.

18 Gallowitsch-Puerta M, Tracey KJ. Immunologic role of the cholinergic anti-inflammatory pathway and the nicotinic acetylcholine $\alpha 7$ receptor. Ann N Y Acad Sci 2005; 1062: 209-219.

19 Wang H, Yu M, Ochani M, et al. Nicotinic acetylcholine receptor $\alpha 7$ subunit is an essential regulator of inflammation. Nature 2003; 421: 384-388.

20 Blanchet MR, Langlois A, Israël-Assayag E, et al. Modulation of eosinophils activation in vitro by a nicotinic receptor agonist. J Leukoc Biol 2007; 81: 1245-1251.

21 Papke RL, Bencherif M, Lippiello P. An evaluation of neuronal nicotinic acetylcholine receptor activation by quaternary nitrogen compounds indicates that choline is selective for the a7 subtypes. Neurosci Lett 1996; 213: 201-204.

22 Wang Y, Su DM, Wang RH, Liu Y, Wang $H$. Antinociceptive effects of choline against acute and inflammatory pain. Neuroscience 2005; 132: 49-56. 
23 Mcfadden ER Jr. Asthma: morphologic-physiologic interactions. Am J Respir Crit Care Med 1994; 150: S23-S26.

24 Cheng JB, Pillar JS, Shirley JT, Showell HJ, Watson JW, Cohan VL. Antigen-mediated pulmonary eosinophilia in immunoglobulin G1-sensitized guinea pigs: eosinophil peroxidase as a simple specific marker for detecting eosinophils in bronchoalveolar lavage fluid. J Pharmacol Exp Ther 1993; 264: 922-929.

25 Wenzel SE, Larsen GL, Johnston K, Voelkel NF, Westcott JY. Elevated levels of leukotriene $\mathrm{C}_{4}$ in bronchoalveolar lavage fluid from atopic asthmatics after endobronchial allergen challenge. Am Rev Respir Dis 1990; 142: 112-119.

26 Wenzel SE, Westcott JY, Larsen GL. Bronchoalveolar lavage fluid mediator levels 5 minutes after allergen challenge in atopic subjects with asthma: relationship to the development of late asthmatic responses. J Allergy Clin Immunol 1991; 87: 540-548.

27 Figueroa DJ, Breyer RM, Defoe SK, et al. Expression of the cysteinyl leukotriene 1 receptor in normal human lung and peripheral blood leukocytes. Am J Respir Crit Care Med 2001; 163: 226-233.

28 Yen CL, Mar MH, Zeisel SH. Choline deficiency-induced apoptosis in PC12 cells is associated with diminished membrane phosphatidylcholine and sphingomyelin, accumulation of ceramide and diacylglycerol, and activation of a caspase. FASEB J 1999; 13: 135-142.

29 Adibhatla RM, Hatcher JF, Larsen EC, Chen X, Sun D, Tsao FH. CDP-choline significantly restores phosphatidylcholine levels by differentially affecting phospholipase $\mathrm{A}_{2}$ and CTP: phosphocholine cytidylyltransferase after stroke. J Biol Chem 2006; 281: 6718-6725.

30 Alvarez XA, Mouzo R, Pichel V, et al. Double-blind placebo-controlled study with citicoline in APOE genotyped Alzheimer's disease patients. Effects on cognitive performance, brain bioelectrical activity and cerebral perfusion. Methods Find Exp Clin Pharmacol 1999; 21: 633-644.
31 Boyd WD, Graham-White J, Blackwood G, Glen I, McQueen J. Clinical effects of choline in Alzheimer senile dementia. Lancet 1977; 2: 7-11.

32 Eberhardt R, Birbamer G, Gerstenbrand F, Rainer E, Traegner H. Citicoline in the treatment of Parkinson's disease. Clin Ther 1990; 12: 489-495.

33 Life Sciences Research Office, Federation of American Societies for Experimental Biology. Effects of Consumption of Choline and Lecithin on Neurological and Cardiovascular Systems. Report No. PB-82-133257. Bethesda, MD, Life Sciences Research Office, Federation of American Societies for Experimental Biology, 1981.

34 Hirata F, Axelrod J. Phospholipid methylation and biological signal transmission. Science 1980; 209: 1082-1090.

35 Morita Y, Chiang PK, Siragonian RP. Effect of inhibitors of transmethylation on histamine release from human basophils. Biochem Pharmacol 1981; 30: 785-791.

36 Lips KS, Luhrmann A, Tschernig T, et al. Down-regulation of the non-neuronal acetylcholine synthesis and release machinery in acute allergic airway inflammation of rat and mouse. Life Sci 2007; 80: 2263-2269.

37 Tucek S. Choline acetyltransferase and the synthesis of acetylcholine. In: Whittaker VP, ed. Handbook of Experimental Pharmacology. The Cholinergic Synapse. Vol. 86. Berlin, Springer Verlag, 1988; pp. 125-165.

38 Kuo KH, Dai J, Seow CY, Lee $\mathrm{CH}$, van Breemen C. Relationship between asynchronous $\mathrm{Ca}^{2+}$ waves and force development in intact smooth muscle bundles of the porcine trachea. Am J Physiol lung Cell Mol Physiol 2003; 285: L1345-L1353.

39 Kalra R, Singh SP, Savage SM, Finch GL, Sopori ML. Effects of cigarette smoke on immune response: chronic exposure to cigarette smoke impairs antigen-mediated signaling in $\mathrm{T}$ cell and depletes $\mathrm{IP}_{3}$-sensitive $\mathrm{Ca}^{2+}$ stores. $J$ Pharmacol Exp Ther 2000; 293: 166-171.

40 Rivera CA, Wheeler MD, Enomoto N, Thurman RG. A choline-rich diet improves survival in a rat model of endotoxin shock. Am J Physiol 1998; 275: 862-867. 